\section{Cold Storage and Moisture Regime Influence Flowering of Oxalis adenophylla and Ipheion uniflorum}

\author{
Allan M. Armitage, Linda Copeland, Paula Gross, and Meg Green \\ Department of Horticulture, University of Georgia, Athens, GA 30602
}

Additional index words. bulb forcing, pot plant production, cooling

\begin{abstract}
Rhizomes of Oxalis adenophylla Gillies and bulbs of Ipheion uniflorum Raf. were planted and wet- or dry-stored at $5{ }^{\circ} \mathrm{C}$ for $0,6,10,14$, or 18 weeks, before being placed in a greenhouse. Regardless of moisture regime, foliage emergence and time to flower decreased for both species with increasing duration of cooling. Wet-stored bulbs/rhizomes within a cooling treatment required less time to foliage and flower emergence when compared with the corresponding dry-storage period. About 10 weeks of $5{ }^{\circ} \mathrm{C}$ was optimum for both species.
\end{abstract}

Oxalis adenophylla, a species of Oxalidaceae, is native to the Andes Mountains of Chile (Bryan, 1989). Plants develop from a small $(\approx 1.5 \mathrm{~cm}$ in diameter), rounded rhizome covered with dark-brown fibers. The graygreen foliage is trifoliate and the leaflets are folded. The rose-pink flowers are $\approx 3 \mathrm{~cm}$ wide and consist of four spreading lobes. Plants grow $\approx 5$ to $10 \mathrm{~cm}$ high.

Ipheion uniflorum (Amaryllidaceae) is native to Argentina and Uruguay. Plants develop from a small, elongated, and pointed bulb (Armitage, 1989). The leaves are grasslike, pale green, and nearly flat, 0.5 to $1 \mathrm{~cm}$ wide and 15 to $23 \mathrm{~cm}$ long. The tubular, pale-blue flowers are $\approx 2.5 \mathrm{~cm}$ wide, and are borne one or two to a stem that rises $15 \mathrm{~cm}$ above the foliage.

Ipheion and Oxalis have been used in gardens and show potential as potted plants due to their relatively small size and charming flowers.

Research on bulb periodicity for many species has been developed and used to force or delay flowering of commercially important bulbous plants (De Hertogh, 1989). The effects of environmental factors on the physiological processes of bulbs were reviewed by De Hertogh et al. (1983) using tulip as a model. The two most important factors affecting bulb growth are temperature and moisture (De Hertogh and Le Nard, 1993). For a species to be used as a potted plant, it must be possible for forcers to provide flowering plants within a specific time interval. The Holland Bulb Forcer's Guide (De Hertogh, 1989) provides no information on storage time or temperature for the forcing of $O$. adenophylla or $I$. uniflorum. Van Leeuwen and Van der Lans (1989) and Van Leeuwen (1991) suggested

Received for publication 26Feb. 1996. Accepted for publication 20 July 1996. Many thanks to Brent Heath, The Daffodil Mart, Gloucester, Va., for supplying the corms and bulbs. Use of trade names does not imply endorsement of the products named nor criticism of similar ones not named. The cost of publishing this paper was defrayed in part by the payment of page charges. Under postal regulations, this paper therefore must be hereby marked advertisement solely to indicate this fact. that the best preplanting storage temperature for $O$. adenophylla rhizomes was $9^{\circ} \mathrm{C}$ for 13 weeks and that flowering occurred $\approx 4$ weeks later in an $18{ }^{\circ} \mathrm{C}$ greenhouse. No published research on the forcing of I. uniflorum was found.

The objective of this study was to determine the influence of duration of cooling and two moisture regimes (wet or dry) on foliage emergence and flowering time of $O$. adenophylla and I. uniflorum.

\section{Materials and Methods}

Oxalis rhizomes and Ipheion bulbs of commercial grade were provided by The Daffodil Mart, Gloucester, Va. Experiments were conducted in a $5 \pm 2{ }^{\circ} \mathrm{C}$ cooler and in the glass greenhouses at the Univ. of Georgia, beginning 29 Nov. 1994 when the bulbs were received. Oxalis rhizomes (360) were divided into two equal groups for wet and dry storage. The wet storage rhizomes were placed three in a $10-\mathrm{cm}(450-\mathrm{mL})$ pot, containing Fafard $3 \mathrm{~S}$ soilless medium (Fafard Co., Anderson, S.C.).
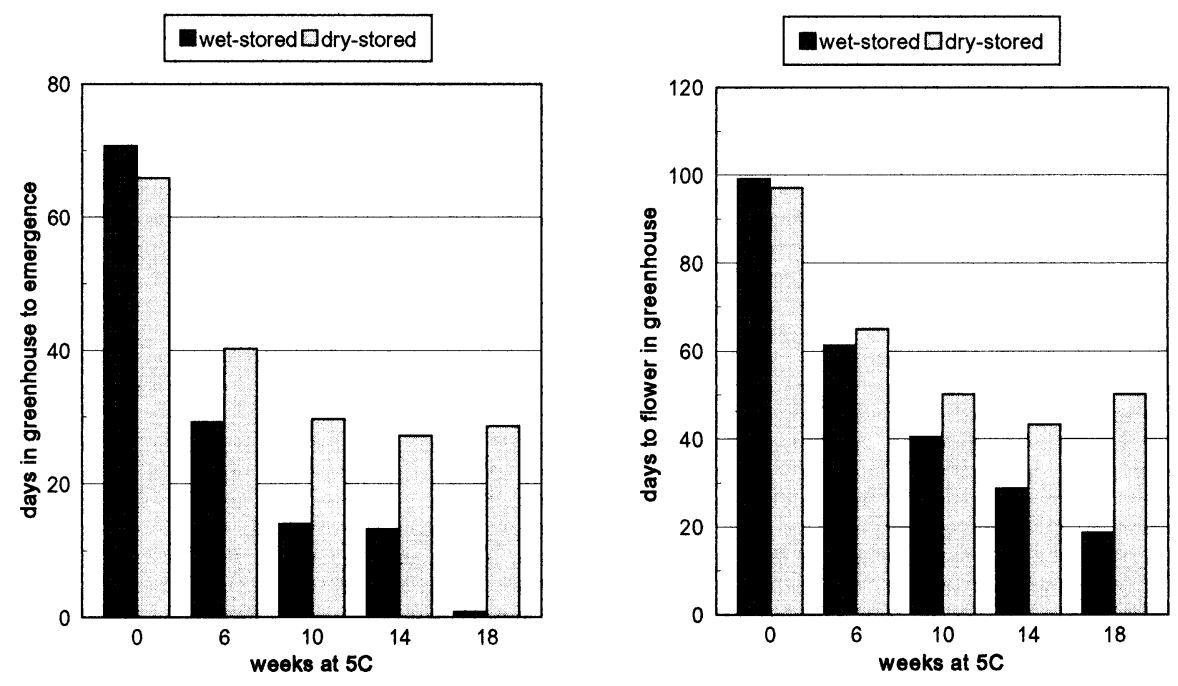

Fig. 1. The influence of length of $5{ }^{\circ} \mathrm{C}$ storage and moisture regime on foliage emergence $(\mathbf{1 A})$ and flowering (1B) of $O$. adenophylla. Trend analysis $(P \leq 0.05)$ : 1A: wet-stored (quadratic; $\left.r^{2}=0.97\right)$; dry-stored (quadratic; $r^{2}=0.90$ ). 1B: wet-stored (quadratic; $r^{2}=0.99$ ); dry-stored (quadratic; $r^{2}=0.93$ ). 

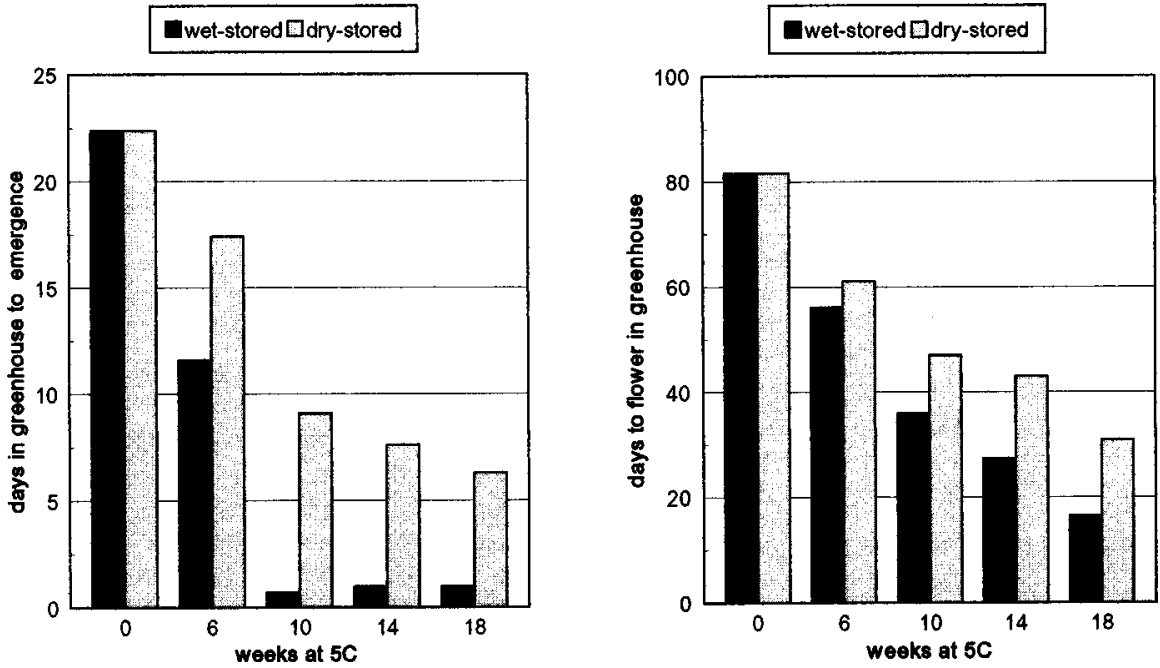

Fig. 2. The influence of length of $5^{\circ} \mathrm{C}$ storage and moisture regime on foliage emergence (2A) and flowering (2B) of I. uniflorum. Trend analysis $(P \leq 0.05)$ : $\mathbf{2 A}$ : wet-stored (quadratic; $r^{2}=0.98$ ); dry-stored (quadratic; $\left.r^{2}=0.91\right)$. 2B: wet-stored (quadratic; $r^{2}=0.99$ ); dry-stored (quadratic; $r^{2}=0.97$ ).

emergence and flowering time occurred between 6 and 10 weeks than between 10 and 18 weeks. Therefore, cooling longer than 10 weeks produced little benefit in foliar emergence or flowering time for either wet or dry-stored rhizomes. Although the data for 18 weeks of wet storage appear optimal, particularly for emergence, the foliage emerged in the cooler, and poor quality plants were obtained. Thus the optimal number of weeks at $5{ }^{\circ} \mathrm{C}$ in this study was less than the 13 weeks reported by Van Leeuwen and Van der Lans (1989) and Van Leeuwen (1991).

Ipheion uniflorum. Days to foliage emergence decreased quadratically for wet- and dry-stored bulbs as the duration at $5^{\circ} \mathrm{C}$ increased (Fig. 2). Although wet- and dry-stored bulbs required less time to emergence with increasing duration at $5{ }^{\circ} \mathrm{C}$, time to foliage emergence were always less for the former under the same cooling duration. Days to flower decreased quadratically with increasing time in the cooler for wet- and dry-stored bulbs (Fig. 2). Days to flower were always less for wet-stored vs. dry-stored rhizomes, within a cold storage.

The quadratic trend suggests a specific optimum cooling time for wet and dry-stored bulbs. Similar optimum times occurred with Ipheion as obtained for Oxalis. Cooling longer than 10 weeks at $5^{\circ} \mathrm{C}$ produced little benefit in hastening foliar emergence. The decrease in time to flower between 0 and 6 weeks was greater than between 6 and 10 weeks' storage, which in turn was greater than that between 10 and 14 weeks' storage. This result suggests that 10 to 14 weeks at $5{ }^{\circ} \mathrm{C}$ are optimum for rapid emergence of flowers. Plant quality was significantly reduced with 18 weeks of storage.

In general, both species exhibited highly desirable characteristics for pot plant use. The data (Figs. 1 and 2) show that 10 to 14 weeks of $5{ }^{\circ} \mathrm{C}$, under either wet or dry conditions, results in the most efficient production of saleable plants. Wet storage produced more rapid foliar emergence and flowering when compared to dry storage and should be used by commercial forcers.

\section{Literature Cited}

Armitage, A.M. 1989. Herbaceous perennial plants. Varsity Press, Athens, Ga.

Bryan, J.E. 1989. Bulbs. vol. II I-Z. Timber Press, Portland, Ore.

De Hertogh, A.A. 1989. Holland bulb forcer's guide 4 th edition. The International Flower-Bulb Centre, Hillegom, The Netherlands.

De Hertogh, A.A., L.H. Aung, and M. Benschop. 1983. The tulip: Botany, usage, growth, and development. Hort. Rev. 5:45-125.

De Hertogh, A.A. and M. Le Nard. 1993. The physiology of flower bulbs. Elsevier Science Publishers B.V., Amsterdam.

Van Leeuwen, P.J. 1991. Oxalis adenophylla goed to forceren als potplant. Weekblad voor Bloembollencultuur 102:30-31.

Van Leeuwen, P.J. and A.M. Van der Lans. 1989. Rijkbloeiende plant geschikt voor de teelt. Weekblad voor Bloembollencultuur 100:36-37. 